\title{
The Relationship between Religions and the Comfort Level of Sexual Orientation
}

\author{
Da Yeon Her \\ Department of Psychology \\ Miami University, Oxford \\ 501 E High St, Oxford OH 45056, USA \\ Hyun Gyung Joo \\ Department of Graduate and Professional Studies \\ California State University, Sacramento \\ 6000 J St, Sacramento CA 95819, USA
}

\begin{abstract}
The purpose of this study intended to verify the relationship between religion (religiosity/spirituality) and the comfort level of sexual orientation. For this purpose, this study collected the data of 74 participants that are above college age through survey link. The participants completed the survey consisting of three scales to assess religiosity, spirituality, and the comfort level of sexual orientation. Subsequently, this article processed the data using SPSS 25.0 version. After calculating Cronbach's a to test the reliability of three instruments, this work produced Pearson's coefficient for testing hypotheses. The results are as follows. First, Religiosity had no significant correlation with the comfort level of sexual orientation. Second, spirituality had the significant negative relationship with the comfort level of sexual orientation. The implications of research results are discussed along with the previous investigations, and then some future directions are suggested with limitations of the current work.
\end{abstract}

Keywords: religion, religiosity, spirituality, sexual identity, sexual orientation, the comfort level, LGBTs

\section{Introduction}

Everyone holds social identities such as gender, nation, ethnicity, social class, sexual orientation, and religion (Abes \& Jones, 2004; Cheng, Sanchez-Burks, \& Lee, 2008b). These social identities, as a usual source of a sense of belonging, were believed to be good for their health and well-being (Haslam, Jetten, Postmes, \& Haslam, 2009). Contrary to this belief, however, social identities can also make some subgroups such as ethnic and sexual minorities experience adverse mental health (Begeny \& Huo, 2017). On second thought, well, we will be able to guess right away that this negative possibility can be due to a prejudice against particular racial and sexual subgroups and to an interest among various subgroups surrounding racial and sexual identity (Campos, 2005; Whitson, Anicich, Wang, \& Galinsky, 2017). Whatever the reason, indeed, social identities have been used as the means of discriminating against some subgroups such as African Americans or lesbians, gays, bisexuals, and transgender (LGBTs)(Elias, Jaisle, \& Morton-Padovano, 2017; Herek, 2000).Unlike ethnicity which has always been a hot button in the history of US, sexual identity is recently emerging as researchers' an area of interest(Campos, 2005; Herek, 2009).

There are sexual orientation and sexual orientation identity as crucial concepts enough to require examining along with sexual identity. Different researchers define sexual identity, sexual orientation, and sexual orientation identity in somewhat different ways. Some researchers use three terms interchangeably (Beagan \& Hattie, 2015; Castellanos-Cruz, Bao, \& Swaab, 2017; Tuthill, 2016). In contrast, Worthington, Savoy, Dillon, and Vernaglia (2002) prefer to make the distinction between sexual identity and sexual orientation. In reality, Worthington et al. (2002) mentioned that sexual orientation is one's sexual predisposition, and sexual identity means one's recognition and identification with such predisposition. Here, sexual identity is a comprehensive concept that implies self-definition more broadly as a sexual being (Anderton, Pender, \& Asner-Self, 2012; Worthington et al., 2002). 
Based on this sexual identity, further, Worthington (2004) suggested that sexual orientation identity, as merely one facet of the constructs of sexual identity, is the term referring to one's acceptance and recognition of sexual orientation. According to the above discussion, despite differing a little from each other, all three concepts imply the concept that individual accepts and recognizes sexual predisposition. Following some investigations including Beagan and Hattie (2015), Castellanos-Cruz et al. (2017), and Tuthill (2016), thus, the current study tries to use these three terms interchangeably.

Because sexual identity is invisible, in fact, it has not been long since it becomes a severe issue, compared to visible racial identity (Ragins, Singh, \& Cornwell, 2007). For this reason, sexual minorities are not addressed as a serious issue in a considerable number of countries in the East yet. Fortunately, contrary to some nations hardly conceding nontraditional sexual orientation of lesbians, gays, bisexuals, and transgender (LGBTs), the Supreme Court of US legalized even the same-sex marriage (Supreme Court of US, June 26, 2015). Despite this legalization, the sad thing is that each state has different standards regarding LGBTs in the US. In these cases, sexual minorities still will come to face far more prejudices in comparison with other social minorities.

As everyone who has ever experienced discrimination can easily guess, sexual minorities can confront with various difficulties in school, workplace, and community (Page, Lindahl, \& Malik, 2013; Ragins et al., 2007). Though people expressing homophobia in public are declining these days, there remains disfavor towards sexual minorities in various situations (Kane, Jacob, \& Sherman, 2015). Facing these adversities, of course, some LGBTs overcome stigma not only through reframing and self-labeling (Wang, Whitson, Anicich, Kray, \& Galinsky, 2017) but also through compensation, strategic interpretation of their social environment, and successful switching identity (Shih, 2004; Shih, Sanchez, \& Ho, 2010). Also, some LGBTs may disclose one's sexual orientation as a result of sexual identity development (Schrimshaw, Downing, \& Cohn, 2018; Worthington et al., 2002). However, many LGBTs still come to self-label themselves as a deviant, improper, and inferior person, suffer from a mood disorder or anxiety, substance misuse, and, consequently, attempt suicide (Begeny \& Huo, 2017; Campos, 2005; Kane et al., 2015; Page et al., 2013). Finally, sexual minorities will be uncomfortable to accept their nontraditional sexual orientation and gradually come to avoid heterosexuals.

Besides, it is worth noting that, growing up in a society where LGBTs are taboo implicitly or plainly, heterosexuals also can hold a negative attitude toward LGBTs (Jäckle \& Wenzelburger, 2014). In some cultures, heterosexuals look coldly upon and sneered at LGBTs (Herek, 2000; 2009; Ragins et al., 2007; Schrimshaw et al., 2018). Heterosexuals' sexual prejudice can work as discrimination against LGBTs and, in turn, can cause other problems. In practice, the research result of Herek (2009) demonstrated that about $20 \%$ of sexual minorities in the US experienced a crime against their person or property after the age of 18 due to their sexual orientation. Harassment is substantially more widespread than a crime, with approximately half of the sexual minority adults who notified verbal abuse. Along with these findings, more upsetting is that a substantial number of LGBTs thought that heterosexuals would finish the friendship and hold homophobic anti-LGBT attitude (Schrimshaw et al., 2018).As a result, these findings seem to reflect that both heterosexuals and LGBTs reveal the discomfort of nontraditional sexual orientation, albeit for different reasons.

By extension, in recent years, among investigations regarding sexual identity, there is a growing body of research on the relationships among multiple social identities (Abes, 2011;Chenget al., 2008a; Cheng, Sanchez-Burks, \& Lee, 2008b; Kane et al., 2015; Page et al., 2013; Shih et al., 2010;Wang et al., 2017). The reason, which such investigations increase, lies in the high possibility that sexual identity conflicts with other social identities such as ability, nation, race, social class, and religion (Abes \& Jones, 2004; Andertonet al., 2012). In other words, though multiple social identities can act as a buffer against poor outcomes, as a rule, one social identity is apt to collide with the other social identities because every social identity has its values, norms, and expectation (Anderton et al., 2012; Cheng et al., 2008a; Cheng et al., 2008b; Shih, 2004; Shih et al., 2010). As such, harmoniously juggling potentially conflicting social identities is very challenging. Out of conflicting each other, this article tries to pick a religion which is most likely to conflict with LGBTs' identity (Abes \& Jones, 2004; Anderton et al., 2012; Kane et al., 2015; Sherry, Adelman, Whilde, \& Quick, 2010).

Of course, religion presents the peace and stability for an individual (Haslam et al., 2009). Undoubtedly, religion has been the root of meaning, psychosocial adjustment, and psychological well-being across all the ages and countries of the world (Cotton, Zebracki, Rosenthal, Tsevat, \& Drotar, 2006; Kane et al., 2015). 
Especially, religion plays a crucial role for adolescents and young adults in that it helps them not only to overcome psychological challenges surrounding academic work, career, interpersonal relationship, and economy but also to find the meaning of life (Kane et al., 2015). Therefore, religion has been regarded as a protective factor against a lot of mental health problems and as a psychological haven for young adults.

However, LGBTs may conflict with religion due to exceptional sexual orientation (Cotton et al., 2006; Hill \& Pargament, 2003; Kane at al., 2015). In fact, more precisely speaking, such conflicts can be attributable to sexual prejudice. As a rule, sexual prejudice is a negative attitude toward individuals based on sexual orientation, and religion has worked as a critical predictor of sexual discrimination (Abes, 2011; Fulton, Gorsuch, \& Maynard, 1999; Herek, 2000; Mak \& Tsang, 2008). In the same vein, some works found that religious conflict may relate to the psychological distress of LGBTs (Sherry et al., 2010) and that the LGBT adolescents, whose parents are religious, were less likely to disclose to others (Schope, 2002).Eventually, these findings imply that religious LGBTs will experience the severe discomfort of their sexual orientation. According to cognitive dissonance theory, LGBTs trying to resolve this psychological discomfort will intentionally seek out other groups who support the present beliefs and value system they hold (Festinger, 1962).

To be specific, LGBTs will disaffiliate from religions that reject their LGBT's identity, become members of a para-church organization, focus on the development of a spirituality identity rather than religious one, or give up religion and spirituality altogether (Anderton et al., 2012). Except for cognitive dissonance, they come to leave the religious organizations because religious LGBTs are scared of being stigmatized by other believers and being discarded by their religion. Although LGBTs themselves also fear to separate from religion which has been their psychological haven for a long time, they cannot help but jump the wall because almost all religions say intolerance of LGBTs in public (Lauricella, Phillips, \& Dubow, 2017; Page et al., 2013). Taken together, intolerance of LGBTs make them shape low self-esteem and suffer from psychological distress and, in turn, leave their religion with ill grace. Even if they continue to practice their religion, LGBTs seldom disclose their sexual orientation (Anderton et al., 2012). Hence, whether LGBTs lead the lifeof religion or not, they will experience the discomfort of their sexual orientation and become conscious of heterosexual believers' eyes.

Even heterosexuals will be influenced by religion (Jäckle \& Wenzelburger, 2014; Mak \& Tsang, 2008). However, since they are less likely to conflict with religion, they can attend religious organizations without the severe discomfort, compared with LGBTs. Since they unceasingly attend religious organizations, a bald intolerance of LGBTs, which religions emphasize, might induce heterosexuals to strengthen intolerance of LGBTs' behavior and, in sequence, can lead to practice harassment, verbal abuse, and a crime which sexual minorities experience. In reality, this reasonable guess was confirmed by findings that heterosexuals revealed hostile behaviors and made mockeries against LGBTs (Elias et al., 2017; Fulton, 1990; Herek, 2000; 2009; Mak\& Tsang, 2008; Schrimshaw et al., 2018). In result, religion can promote heterosexuals to strengthen prejudice against LGBTs, without any compunction toward LGBTs. On the contrary, according to Inglehart's theory of value change, a new generation growing in a threat-less and affluent society tends to hold post-material values, which influence the various attitudes (Inglehart, 1977). Connecting it with religion and sexual orientation, Inglehart and Norris (2003) postulate that the more post-material individual, the lower religiosity and the discomfort of LGBTs. For establishing these conflicting opinions, as such, we require exploring how much religion correlates with the comfort degree of sexual orientation which young adults, whether heterosexuals or LGBTs, hold.

Furthermore, according to some researchers, religious orientation is a crucial variable in the relationship between religion and sexual bias (Mak \& Tsang, 2008; Tsang \& Rowatt, 2007). To be more specific, the empirical evidence demonstrated that intrinsic religious orientation correlated with high sexual prejudice whereas extrinsic religious orientation unrelated to sexual prejudice (Tsang \& Rowatt, 2007). About its cause, Mak and Tsang (2008) pointed out that the perceived value-violation might contribute to the relationship between religious orientation and sexual prejudice on the part of intrinsically religious individuals. In a similar vein, Fulton et al. (1999) already analyzed ages ago that, even if intrinsically religious individuals are tolerant toward LGBTs as individuals thanks to perspective taking, they were intolerant of LGBTs' behavior, which would violate their religious values. Therefore, it is a possibility that intrinsically believers experience the discomfort of LGBTs while extrinsically believers feel the discomfort of LGBTs.

This position can be extended to researchers' view which distinguishes religiosity from spirituality in studying religion (Hill \& Pargament, 2003; Hodge, 2003; Hodge \& Boddies, 2008; McIntosh, Poulin, Silver, \& Holman, 2011). 
According to Hill and Pargament (2003), religiosity means institutionally related practices and behaviors whereas spirituality implies subjective and personal beliefs. If we connected these two concepts with religious orientation as mentioned above, religiosity would link with extrinsic religious orientation while spirituality would connect with intrinsic religious orientation (Jäckle \& Wenzelburger, 2014; Tsang \& Rowatt, 2007).From this extension, both religiosity and spirituality are expected to relate to the comfort level of sexual orientation (Fulton et al., 1999; Jäckle \& Wenzelburger, 2014; Mak \& Tsang, 2008; Tsang \& Rowatt, 2007). Based on the discussion to date, the current work intends to verify how much religiosity and spirituality of young adults correlate with their comfort level of sexual orientation. For this purpose, we set hypotheses as follows.

Hypothesis 1.The religiosity of young adults will have the significant negative correlation with their comfort level of sexual orientation.

Hypothesis 2.The spirituality of young adults will have the significant negative correlation with their comfort level of sexual orientation.

\section{Method}

\subsection{Participants}

After selecting or reconstructing three scales to assess religiosity, spirituality, and the comfort level of sexual orientation, we uploaded them into Qualtrics. Subsequently, we sent a survey link to 76 students who are attending a middle-sized public university located in the eastern part of US and collected the available data of 74 respondents from April 2-20, 2018.Demographic analysis showed that 65\% of respondents were female (male $=26$, female $=48)$, and the mean age of respondents was $22.14(\mathrm{SD}=9.345)$. This standard deviation was so high because the current research included some participants that were above college age. Respondents selfidentified sexual orientation as homosexual $(n=1)$, heterosexual $(n=67)$, asexual $(n=1)$, pansexual $(n=1)$, and "other" $(\mathrm{n}=4)$. Since sexual orientation was an invisible variable (Ragins et al., 2007), inevitably, representative sampling could not but be beyond the scope of a researcher's capacity.

\subsection{Scales}

In the survey, there were three scales including religiosity scale, intrinsic spirituality scale, and the comfort level of sexual orientation scale as follows.

\subsubsection{Religiosity scale}

This instrument is a six-item scale to answer on a 3 7 point Likert scale, consisting of three items assessing religious practices (Elias et al., 2017) and three questions regarding how many times they think they participate in the religious services. This study analyzed some items (number 4 and 5) after re-coding them. An example of questions in this scale is "Would you consider yourself a strong member of the religious group you affiliate yourself with?" The Cronbach's $\alpha$ of this scale is .889 .

\subsubsection{Intrinsic spirituality scale}

This study used the intrinsic spirituality scale measuring the salience of spirituality as a motivational construct (Hodge, 2003). It is a six-item instrument to answer on a 10 point Likert scale. An example of items is "My spiritual beliefs affect 0 (no aspect of my life) 10 (absolutely every aspect of my life)." In the case of this scale, the higher a score is, the higher spirituality is. The Cronbach's $\alpha$ of this scale is .978 .

\subsubsection{The comfort level of sexual orientation scale}

This research used a 6-item scale, which is reconstructed based on the studies of Abes (2011), Campos (2005), Lauricella et al. (2017), Page, Lindahl, and Malik (2013), and Worthington (2004) to assess the comfort level of sexual orientation. Besides, participants need to answer on a 5 point Likert scale which researchers reconstructed. A sample item is "How much do you support the marriage of two people of the same sex?" Respondents with a higher score in this instrument are more likely to be the comfort level of nontraditional sexual orientations. The Cronbach's $\alpha$ of this scale is .901 .

\subsection{Data analysis}

This research calculated descriptive statistics before testing the research hypotheses. Subsequently, we produced Cronbach's $\alpha$ for religiosity scale, intrinsic spirituality scale, and the comfort level of sexual orientation scale. 
For testing hypotheses, in the end, we yielded Pearson's correlation coefficients between religiosity, spirituality, and the comfort level of sexual orientation. The current study used SPSS version 25.0 for processing data. This study set the significance level of .05.

\section{Results}

The descriptive statistics for all variables in this work and Pearson's correlation analysis between them are presented in Table 1.At the bottom of Table 1, there are the means and standard deviations for all variables.

Table 1. Descriptive data and Pearson's correlation coefficients between variables $(N=74)$

\begin{tabular}{|lcll|}
\hline & Religiosity & Spirituality & The comfort level of sexual orientation \\
\hline Religiosity & 1 & & \\
Spirituality & $.610^{*}$ & 1 & \\
The comfort level of sexual orientation & -.097 & $-.405^{*}$ & 1 \\
\hline M & 4.035 & 5.078 & 2.696 \\
SD & .810 & 2.961 & .568 \\
\hline
\end{tabular}

*Correlation is significant at the 0.05 level.

Subsequently, all the correlations between religiosity, spirituality, and the comfort level of sexual orientation are as follows (Table 1). First, religiosity had a significant positive association with spirituality $(\mathrm{r}=610, \mathrm{p}<.05)$. Second, religiosity did not significantly relate to the comfort level of sexual orientation ( $\mathrm{r}=-.097, \mathrm{p}>.05)$. Third, spirituality revealed a significant negative relationship with the comfort level of sexual orientation $(\mathrm{r}=-.405$, $\mathrm{p}<.05)$. As provided above, religiosity had no significant association with the comfort level of sexual orientation whereas spirituality showed a significant negative correlation with the comfort level of sexual orientation.

\section{Discussion}

The present study intended to identify the correlations of religiosity and spirituality with the comfort level of sexual orientation. Here, focusing on this purpose of this work, the research results are discussed with previous investigations as follows. Before going on to a discussion concerning the research hypotheses, we will discuss the relationship between the religiosity and spirituality which are predictors, as described below. First, the finding revealed that religiosity had a significant positive association with spirituality. This empirical evidence supports the concepts that the religiosity and spirituality have a close relationship with each other, even though both are entirely different components of religion(Cotton et al., 2006; Hill \& Pargament, 2003; McIntosh et al., 2011).To be specific, religiosity relates to action/physical practices while spirituality connects with beliefs and views on the world (Cotton et al., 2006; Hodge, 2003; Hodge \& Boddie, 2008; Inglehart \& Norris, 2003; Jäckle\& Wenzelburger, 2014; Tuthill, 2016). That is, religiosity approximates to the form of religion whereas spirituality is near the nature of religion. In sum, though the meanings of the two terms differ a little from each other, it was confirmed that they are close to each other through this study.

In fact, the move to separate religiosity from spirituality was not very long. Namely, as researchers studying in physical and mental health recently got interested in religions, the position distinguishing religiosity from spirituality came to be cemented. In a similar context, with supporting that religiosity and spirituality are unique constructs, McIntosh (2011) also identified that these two factors played different roles in the physical and mental health. Following this trend, recently, the works analytically approaching to religion are emerging (Cotton et al., 2006; Hill \& Pargament, 2003; Hodge, 2003; Ingle hart\& Norris, 2003; Jäckle \& Wenzelburger, 2014; Tuthill, 2016). At this time when the pendulum is swinging to an analytic approach to religion, the result of this work reporting a significant positive correlation between two predictors seems to provide investigators with a chance to make a profound reflection on the relationship and interaction between two predictors. Hence, this finding will be the cornerstone on which investigations in different directions show synergy effects by striking a delicate balance between analysis and synthesis in religion research.

Second, religiosity had no significant correlation with the comfort level of sexual orientation, opposite to the hypothesis of this work. To the best of our knowledge, in reality, less is known about study identifying the relationship between religiosity and the comfort level of sexual orientation. Thus, this finding is difficult to compare with the previous results directly. However, the example which is indirectly comparable to the present study can be the study of Jäckle and Wenzelburger (2014) analyzing data from 79 countries. Unlike this study, Jäckle and Wenzelburger (2014) demonstrated that people with the higher religiosity were disposed to be more homonegative, which means the high discomfort level of nontraditional sexual orientation. 
In fact, since their investigation had many extraneous variables including nations, religions, cultures, and races, there are limitations to generalize the results of their work. In their study, moreover, homonegativity depended on even socio-demographic characteristics such as gender, age, income, educational level, with or without children and so on. As a result, as Jäckle and Wenzelburger (2014) admitted it to themselves, it is difficult to generalize that religious people were more homonegative across all subgroups.

Apart from the study of Jäckle and Wenzelburger (2014), historically, since religious institutions have considered nontraditional sexual orientation to be sacrilegious, LGBTs are more inclined to be a discomfort to a religious community (Lauricella et al., 2017; Mak\& Tsang, 2008; Schrimshaw et al., 2018). Consequently, it is no wonder that high religiosity would have the significant negative association with the comfort level of LGBTs. Indeed, as Herek (2000; 2009), Ragins et al. (2007), and Schrimshaw et al. (2018) demonstrated, heterosexuals' sexual prejudice was severe and, in turn, LGBTs feared such anti-LGBT attitude. To top it off, if religious heterosexuals repeatedly hear a story which regards LGBTs as sin in religious organizations, they cannot help being the discomfort of LGBTs.

Nonetheless, the result of this work, showing no significant correlation between religiosity and the comfort level of sexual orientation, seems to be attributable to some possibilities as follows. First of all, extrinsically religious orientation might mediate no significant relationship between religiosity and the comfort level of sexual orientation. Typically, since religiosity means institutionally related practices and behaviors (Hill \& Pargament, 2003), religiosity accords with extrinsically religious orientation (Tsang \&Rowatt, 2007). As some researchers (Fulton et al.,1999; Mak \& Tsang, 2008) pointed out, eventually, extrinsic believers whether heterosexuals or LGBTs are more inclined to feel the comfort of LGBT behaviors because extrinsic believers did not experience value-violation. Next, we can view this finding in a new generation's post-material perspective, too. As Inglehart and Norris (2003) postulated, college students are more likely to hold the post-material value and, sequentially, to get out of formality, which is close to religiosity. Consistent with Inglehart and Norris (2003), the result of this work whose most participants are college students showed no significant correlation, opposite to Jäckle and Wenzelburger's work (2014) whose participants had a wide range of ages.

Besides, this empirical evidence can relate to cognitive dissonance theory. Cognitive dissonance theory (Festinger, 1962) supposed that individuals experiencing a conflict between religiosity and sexual orientation will change their cognition, thought, or behavior to resolve the dissonance. Since most participants in this work are heterosexuals, however, it is a low possibility that they feel the dissonance as much as LGBTs. Accordingly, they keep practicing their religion. Even while living their religion, their religiosity seems to have no significant association with the comfort of LGBTs because religiosity hardly induces value-violation (Anderton et al., 2012; Fulton et al., 1999; Mak \& Tsang, 2008).From an adaptive point of view, lastly, this finding can be a real feat of effective strategies which heterosexuals used. Explaining no significant relationship between religiosity and the comfort level of sexual orientation, as a rule, some researchers may interpret that LGBTs might negotiate religiosity and sexual identity, as Tuthill (2016) suggested. In that case, indeed, the negotiation of LGBTs can be available, using stigma management strategies or sexual identity development (Shih, 2004; Shih et al., 2010; Schrimshaw et al., 2018; Wang et al., 2017; Whitson et al., 2017).Since most participants are heterosexuals in this work, however, it is highly likely that the perspective taking of heterosexuals improves intergroup attitudes by inducing their empathy (Shih et al., 2009). Since they put themselves in LGBTs' shoes, merely religiosity did not cause the discomfort of LGBTs.

Though all four possibilities, as just noted, can contribute to no significant correlation between religiosity and the comfort level of sexual orientation, at least one or more possibilities were likely to influence the result of this study respectively or interactively. More specifically speaking, religious orientation, post-material value, cognitive dissonance, and negotiation strategy and perspective taking have a real chance of working as the mediating or moderating variables. As such, since the relationship between religiosity and the comfort level of sexual orientation can depend on the mediating or moderating variables, future research will have to examine the effect of religious orientation, post-material value, cognitive dissonance, and negotiation strategy and perspective taking as mediating or moderating variables.

Third, spirituality revealed a significant negative relationship with the comfort level of sexual orientation. This empirical evidence means that people with higher spirituality are inclined to showthe lower comfort level of nontraditional sexual orientation. Since little was known about the research that can be directly compared with our work, as we know, we will intend to discuss this finding with similar investigations. 
First of all, this finding backs up the concepts that spirituality means an intrinsic religious orientation and a person's relationship with God rather than practices and rituals (Hill \& Pargament, 2003; Hodge, 2003; Hodge \& Boddie, 2008). At the same time, empirically, this study whose most participants are heterosexuals supports the previous investigations that heterosexuals held the severe negative attitude toward LGBTs (Herek, 2009; Schrimshaw et al., 2018).

Like in the religiosity, even here, we will discuss this evidence with four possibilities including religious orientation, post-material value, cognitive dissonance, and negotiation strategy and perspective taking as follows. In general, people with intrinsic religious orientation do not use religion but live it (Allport \& Ross, 1967). Since intrinsic religious orientation coincides with the spirituality, in consequence, this finding supports the opinion that LGBT behaviors conflict with the value of peoples, whether LGBTs or heterosexuals, who hold intrinsic religious orientation(Fulton et al., 1999; Mak\& Tsang, 2008;Tsang \& Rowatt, 2007). Next, when we look at this finding with the post-material value, the post-material value seldom had the significant influence upon the relationship between the spirituality and the comfort of LGBTs. Perhaps the post-material value did not go beyond the intrinsic spirituality yet, being some distance from the view that it urges the influence of religion and prejudice toward LGBTs to decline (Inglehart \& Norris, 2003).

In contrast, the higher spirituality, the higher shame, guilt, cognitive dissonance, and discomfort on the part of LGBTs (Beagan \& Hattie, 2015; Sherry et al., 2010).Even if heterosexuals also feel cognitive dissonance to some degree, typically, they continue to practice their religion, as they are not the person in question. After all, they often hear stories intolerant of LGBTs. In that situation, heterosexuals who hold higher spirituality are likely to be the higher discomfort of LGBTs because spirituality induces value-violation (Anderton et al., 2012; Fulton et al., 1999; Mak \& Tsang, 2008).Lastly, since almost all the participants in this research are heterosexuals, the perspective taking than negotiation strategy appears to be appropriate to explain this finding. In general, heterosexuals, who hold the higher perspective taking, tend to put themselves in LGBTs' shoes (Shih et al., 2009). Nevertheless, heterosexuals whose spirituality is high seem to be intolerant of LGBTs' behavior, even though they are tolerant towards LGBTs as individuals (Fulton et al., 1999).By extension, if heterosexuals feel the higher discomfort of LGBTs, it might provoke discrimination against sexual minorities and social conflict (Abes, 2011; Schrimshaw et al., 2018).In sum, about two out of four possibilities, that is, intrinsic religious orientation and cognitive dissonance are more likely to contribute to the relationship between spirituality and the comfort degree of sexual orientation respectively or interactively. Hence, further investigation needs to identify the mediating or moderating effects of these variables on the relationship between spirituality and the comfort level of sexual orientation.

As discussed above, this article has implications that, although religiosity is close to spirituality, two concepts are quite distinct from each other, considering that each showed the different association with the comfort level of sexual orientation. This difference in each correlation between religiosity and spirituality and the comfort of sexual orientation mainly seems to link with intrinsic religious orientation and cognitive dissonance out of four possibilities as described above. In consequence, these findings indicate the possibility that the higher not religiosity but spirituality, the lower the comfort, due to intrinsic religious orientation and cognitive dissonance. Furthermore, we can get insight into that spirituality meaning intrinsic religious orientation is more likely to conflict with LGBTs, compared with religiosity. Unfortunately, this insight makes us concerned about that this discomfort of LGBTs would aggravate discrimination and social conflicts. Afterward, therefore, the religious and counseling areas should have an in-depth discussion on the relationship between spirituality and the comfort level of sexual identity for respecting the sexual minorities and integrating a society.

\section{Limitations and Future directions}

Though the present study has some implications, there are some limitations, too. Based on the limitations of this study, as such, we suggested future directions as follows.

First, there is a need to introduce a qualitative approach to complement the limitation of a self-report method. In most societies, sexual orientation is stillroom for social controversy. Accordingly, when participants respond to items concerning nontraditional sexual orientation, there can be some gap between responses and actual behaviors. For that reason, although participants showed the higher comfort level of LGBTs, they may treat LGBTs with discomfort. 
Thus, future study will have to assess actual behaviors through a qualitative approach such as narrative analysis, in-depth interview, and participant observation (Abes, 2011; Beagan \& Hattie, 2015; Schrimshaw et al., 2018; Sherry et al., 2010; Tuthill, 2016).

Second, a future study needs to extend the sample size and use a representative sampling method for ensuring a generalization. In the case of the current work, the sample size is somewhat small, and most participants are college students. Besides, when we consider that the most participants were heterosexuals, the results of the current work did not reflect the opinions of LGBTs adequately. Since sexual orientation is an invisible variable, inevitably, we could not confirm the participants' sexual orientation before analyzing the data. When we consider these limitations, the findings of this article are difficult to generalize. Hence, later research will need to extend the sample size and diversify the sampling target to a generalizable level.

Third, future works require verifying the mediating or moderating effect of religious orientation, post-material value, cognitive dissonance, and negotiation strategy and perspective taking on the relationship between religiosity and spirituality and the comfort level of sexual orientation. The reason is that the correlation of religiosity and spirituality with the comfort level of sexual orientation can depend on such mediating or moderating variables. Building on works to date, thus, later research needs to establish the effect of mediating or moderating variables on the relationship of religiosity and spirituality with the comfort level of sexual orientation.

\section{Conclusion}

This investigation verified that religiosity had the significant positive association with spirituality, and spirituality, unlike religiosity, showed the significant negative relationship with the comfort level of sexual orientation. We discussed these results with four possibilities which are helpful to explain the difference in the relationship between religiosity and spirituality and the comfort level of sexual orientation. As a result of discussing them, intrinsic religious orientation and cognitive dissonance out of four possibilities, namely, religious orientation, cognitive dissonance, post-material value, and negotiation strategy and perspective taking, seemed to contribute to the difference in the correlation between religiosity and spirituality and the comfort of sexual orientation. Therefore, the further investigation requires examining how suchvarious variables mediate or moderate the relationship between religiosity and spirituality and the comfort level of sexual orientation.

\section{Acknowledgments}

We owe a huge debt of gratitude to Devin Bussell, Sally Micsko, Robert Knight, Christina Roylance, and Alejandro Trujillo for their critical role in making this article happen.

\section{References}

Abes, E. S. (2011). Exploring the relationship between sexual orientation and religious identities for Jewish lesbian college students.Journal of Lesbian Studies, 15, 205-225. http://dx.doi.org/10.1080/10894160.2010.510773

Abes, E. S., \& Jones, S. R. (2004). Meaning-making capacity and the dynamics of lesbian college students' multiple dimensions of identity. Journal of College Student Development, 45, 612-632. http://dx.doi.org/10.1353/csd.2004.0065

Anderton, C. L., Pender, D. A., \& Asner-Self, K. K. (2012). A review of the religious identity/sexual orientation identity conflict literature: Revisiting Festinger's cognitive dissonance theory. Journal of LGBT Issues in Counseling, 5(3-4), 259-281. http://dx.doi.org/10.1080/15538605.2011.632745

Allport, G., \& Ross, J. M. (1967). Personal religious orientation and prejudice. Journal of Personality and Social Psychology, 5, 423-443.http://dx.doi.org/10.1037/h0021212

Beagan, B. L., \& Hattie, B. (2015). Religion, spirituality, and LGBTQ identity integration. Journal of LGBT Issues in Counseling, 9(2), 92-117. http://dx.doi.org/10.1080/15538605.2015.1029204

Begeny, C. T., \&Huo, Y. J. (2017). When identity hurts: How positive intragroup experiences yield negative mental health implications for ethnic and sexual minorities. European Journal of Social Psychology, 47(7), 803-817. http://dx.doi.org/10.1002/ejsp.2292

Campos, D. (2005). Understanding gay and lesbian youth: Lessons for straight school teachers, counselors, and administrators. Maryland: Rowman \& Littlefield Education. 
Castellanos-Cruz, L., Bao, A., \&Swaab, D. (2017). Sexual identity and sexual orientation. In D. W. Pfaff \& M. Joëls(Eds.), Hormones, brain, and behavior(3rd Ed.). NY: Elsevier. http://dx.doi.org/10.1016/B978-0-12803592-4.00104-8

Cheng, C.-Y., Sanders, M., Sanchez-Burks, J., Molina, K., Lee, F., Darling, E., \& Zhao, Y. (2008a). Reaping the rewards of diversity: The role of identity integration. Social and Personality Psychology Compass, 2(3). 1182-1198. http://dx.doi.org/10.1111/j.1751-9004.2008.00103.x

Cheng, C.-Y., Sanchez-Burks, J., \& Lee, F. (2008b). Connecting the dots within: Creativeperformance and identity integration.Psychological Science, 19(11), 1178-1184. http://dx.doi.org/10.1111/j.1467-9280.2008.02220.x

Cotton, S., Zebracki, K., Rosenthal, S. L., Tsevat, J., \&Drotar, D. (2006). Religion/spirituality and adolescent health outcomes: A review. Journal of Adolescent Health, 38, 472-480. http://dx.doi.org/10.1016/j.jadohealth.2005.10.005

Elias, T., Jaisle, A., \& Morton-Padovano, C. (2017). Ethnic identity as a predictor of microaggressions toward Blacks, Whites, and Hispanic LGBs by Blacks, Whites, and Hispanics. Journal of Homosexuality, 64(1), 1-31. http://dx.doi.org/10.1080/00918369.2016.1172888

Festinger, L. (1962). Cognitive dissonance. Scientific American, 207(4), 93-107. http://dx.doi.org/10.1038/scientificamerican1062-93

Fulton, A. S., Gorsuch, R. L., \& Maynard, E. A. (1999). Religious orientation, antihomosexual sentiment, and fundamentalism among Christians. Journal for the Scientific Study of Religion, 38(1), 14-22. http://dx.doi.org/10.2307/1387580

Haslam, S. A., Jetten, J., Postmes, T., \& Haslam, C. (2009). Social identity, health, and well-being: An emerging agenda for applied psychology. Applied Psychology, 58, 1-23. http://dx.doi.org/10.1111/j.1464-0597.2008.00379.x

Herek, G. M. (2000). The psychology of sexual prejudice. Current Directions in Psychological Science, 9(1), 1922. https://doi.org/10.1111/1467-8721.00051

Herek, G. M. (2009). Hate crimes and stigma-related experiences among sexual minority adults in the United States: Prevalence estimates from a national probability sample. Journal of Interpersonal Violence,24, 54-74. http://dx.doi.org/10.1177/0886260508316477

Hill, P. C., \&Pargament, K. I. (2003). Advances in the conceptualization and measurement of religion and spirituality: Implications for physical and mental health research. American Psychologist, 58, 64-74. http://dx.doi.org/10.1037/0003-066X.58.1.64

Hodge, D. R. (2003). The intrinsic spirituality scale: A new six-item instrument for assessing the salience of spirituality as a motivational construct. Journal of Social Service Research 30(1), 41-61. http://dx.doi.org/10.1300/J079v30n01_03

Hodge, D. R.,\&Boddie, S. C.(2008).Social workers'personal spiritual characteristics and their conceptualizations of spirituality and religion.Journal of Religion \& Spirituality in Social Work: Social Thought,26(1),5370.http://dx.doi.org/10.1300/J377v26n01_04

Inglehart, R. (1977). The silent revolution: Changing values and political styles among Western publics. Princeton, NJ: Princeton University Press.

Inglehart, R., \& Norris, P. (2003). Rising tide - Gender equality and cultural change around the world. Cambridge, UK: Cambridge University Press. Retrieved from https://www.hse.ru/data/2013/02/20/1306830406/Inglehart\&Norris_Rising\%20Tide.pdf.

Jäckle, S.,\&Wenzelburger, G. (2014). Religion, religiosity, and the attitudes toward homosexuality - A multilevel analysis of 79 countries. Journal of Homosexuality, 62(2), 207-241. http://dx.doi.org/10.1080/00918369.2014.969071

Kane, M., Jacob, R. J., \& Sherman, D. (2015). Religious belief, age, and sexual orientation on attributions of younger and older gay and heterosexual men. Mental Health, Religion \& Culture, 18(3), 151-164. http://dx.doi.org/10.1080/13674676.2015.1022522

Lauricella, S. K., Phillips, R. I., \&Dubow, E. F. (2017). Religious coping with sexual stigma in young adults with same-sex attractions. Journal of Religion and Health, 56(4), 1436-1449.

http://dx.doi.org/10.1007/s10943-017-0374-4 
Mak, H. K., \& Tsang, J. (2008).Separating the "sinner" from the "sin": Religious orientation and prejudiced behavior toward sexual orientation and promiscuous sex. Journal for the Scientific Study of Religion 47(3),379-392. https://doi.org/10.1111/j.1468-5906.2008.00416.x

McIntosh, D. N., Poulin, M. J., Silver, R. C., \& Holman, E. A. (2011). The distinct roles of spirituality and religiosity in physical and mental health after collective trauma: A national longitudinal study of responses to the 9/11 attacks. Journal of Behavioral Medicine, 34(6), 497-507. http://dx.doi.org/10.1007/s10865-011-9331-y

Page, M. L., Lindahl, K. M., \& Malik, N. M. (2013). The role of religion and stress in sexual identity and mental health among lesbian, gay, and bisexual youth. Journal of Research on Adolescence, 23(4), 665-677. http://dx.doi.org/10.1111/jora.12025

Ragins, B. R., Singh, R., Cornwell, J. M. (2007). Making the invisible visible: Fear and disclosure of sexual orientation at work. Journal of Applied Psychology, 92(4), 1103-1118. http://dx.doi.org/10.1037/00219010.92.4.1103

Schope, R. D. (2002). The decision to tell: Factors influencing the disclosure of sexual orientation by gay men. Journal of Gay \& Lesbian Social Services, 14(1), 1-22. http://dx.doi.org/10.1300/J041v14n01_01

Schrimshaw, E. W., Downing, M. J. Jr., \& Cohn, D. J. (2018). Reasons for non-disclosure of sexual orientation among behaviorally bisexual men: Non-disclosure as stigma management. Archives of Sexual Behavior, 47, 219-233. http://dx.doi.org/10.1007/s10508-016-0762-y

Sherry, A., Adelman, A., Whilde, M. R., \& Quick, D. (2010). Competing selves: Negotiating the intersection of spiritual and sexual identities. Professional Psychology: Research and Practice, 41, 112-119. http://dx.doi.org/10.1037/a0017471

Shih, M. (2004). Positive stigma: Examining resilience and empowerment in overcoming stigma. Annals of the Academy of Political and Social Science, 591, 175-185. http://dx.doi.org/10.1177/0002716203260099

Shih, M., Sanchez, D. T., \& Ho, G. C. (2010). Costs and benefits of switching among multiple social identities. In R. J. Crisp, (Ed.). The Psychology of Social and Cultural Diversity, Blackwell. http://dx.doi.org/10.1002/9781444325447.ch4

Shih, M., Wang, E., Trahan, A., \&Stotzer, B. (2009). Perspective taking: Reducing prejudice towards general outgroups and specific individuals. Group Processes and Intergroup Relations, 12(5), 565-577. http://dx.doi.org/10.1177/1368430209337463

Supreme Court of US (2015, June 26). Obergefell v. Hodges, No. 14-556, slip op. at 22. Retrieval from at https://www.supremecourt.gov/opinions/14pdf/14-556_3204.pdf.

Tsang, J., \&Rowatt, W. W. (2007). The relationship between religious orientation, right-wing authoritarianism, and implicit attitudes toward lesbians and gay men. International Journal for the Psychology of Religion, 17(2), 99-120. https://doi.org/10.1080/10508610701244122

Tuthill, Z. (2016). Negotiating religiosity and sexual identity among Hispanic lesbian mothers. Journal of Homosexuality, 63(9), 1194-1210. http://dx.doi.org/10.1080/00918369.2016.1151691

Wang,C. S, Whitson, J. A., Anicich, E. M., Kray, L. J., \&Galinsky, A. D. (2017). Reframe and revalue negative stereotypes and slurs. Current Directions in Psychological Science, 6(1), 75-80. https://doi.org/10.1177/0963721416676578

Whicker, D. R., de St. Aubin, E., \&Skerven, K. (2017). The role of internalized homonegativity in the faith and psychological health of lesbians. Journal of lesbian studies, 21(4), 478-494. https://doi.org/10.1080/10894160.2017.1350795

Whitson, J. A., Anicich, E. M., Wang, C. S., \&Galinsky, A. D. (2017). Navigating stigma and group conflict: Identification and self-labeling. Negotiation and Conflict Management Research, 10,88-106. http://dx.doi.org/10.1111/ncmr.12094

Worthington, R. L. (2004). Sexual identity, sexual orientation, religious identity, and change: Is it possible to depolarize the debate? The Counseling Psychologist, 32(5), 741-749. http://dx.doi.org/10.1177/0011000004267566

Worthington, R. L., Savoy, H. B., Dillon, F. R., \&Vernaglia, E. R. (2002). Heterosexual identity development: A multidimensional model of individual and social identity. The Counseling Psychologist, 30(4), 496-531. http://dx.doi.org/0.1177/00100002030004002 